\title{
Contrastive and Degenerative Transitivity as Thematic Reinforcement in Selected J. P. Clark Poetry
}

\author{
Obinna Iroegbu \\ Department of English and Literary Studies, Federal University, Oye-Ekiti, Ekiti State, Nigeria
}

\begin{abstract}
This article examines the stylistic implications of transitivity in selected poems by J.P. Clark, a foremost Nigerian poet. Transitivity is engaged from the perspective of Halliday's ideational meta-function of language use, with attention paid to the participants and the processes. Twelve randomly selected poems from Clark's (2010) Full Tide are analyzed. It is observed that, in some of these poems, there is deliberate foregrounding of the sequence or location of lexical forms, especially those pertaining to participants and processes. This foregrounding is established in what manifests as a negative shift in lexico-semantic forms that suggests degenerative essence. The placement of words as well as the sequence of these words evokes a secondary reading beyond what the text ordinarily expresses.
\end{abstract}

Index Terms - J. P. Clark, degenerative transitivity, lexico-semantic features

\section{INTRODUCTION}

Style has variously been defined as the mark or stamp of the author which stands out a particular piece of writing (Kamalu, 2018, Simpson, 2014 and Uffot, 2006). In this regard, it can be argued that the achievement of a noticeable style demands both conscious and, to an extent, subconscious exertion of a manner of presentation on the part of the author. Conscious exertion means that achievement of style requires a deliberate observation of certain linguistic convention as is related to the particular genre of writing and as desired by the author. This conception of style corresponds to the submission of Udumukwu (2015) when he explains that style consists in an author's conscious manipulation of the resources of language with a clear intention of generating specific meanings in a text.

However, when style is considered as a product of the subconscious, it is recognized that what constitutes a manifestation of observable stylistic trait might not be a contrivance or deliberate effort but an innate mannerism acquired and exercised over the course of an author's writing career. That is, it is a sort of authorial idiolect. In any case, between these two distinctions of what may engender style, the later appears to offer a greater motivation for certain peculiarities in texts. Of course, one cannot deny the necessary requirement of deliberation in writing as in every other aspect of human engagement. Beyond the point of deliberation, however, a kind of automation takes over. Language offers the vehicle of expression by means of lexicon; it also offers metaphor or extended meaning which might depend on context or special usage. Moreover, personal mastery or exposure - which especially applies to English as Second Language (ESL) users such as Clark, contributes to the limit or extent of expertise; it is at the culmination of these dynamics that style somewhat essentially manifests. Apart from this, it is a given that literary language confesses an understandable peculiarity which marks it out, drawing the attention of a careful analyst to its distinction. To underscore the fact that the language of literature is different from normal language, Udumukwu observes that "the language of literature has become mediated to the extent that it can no longer be constructed on the basis of the rules of natural language" $(2015$, p.9). Udumukwu's view here is in tandem with Terry Eagleton's (1990) conception of what qualifies as literary language. Thus, the language of literature confesses a style or form motivated by choice and, to an extent, a subconscious stimulus. This subconscious stimulus tends to result from the systemic nature of language in relation to the syntagmatic and paradigmatic levels. The consequent manifestation of an observable pattern, either as paradigmatic or syntagmatic relation, therefore generates style, the latter of which instigates a special appreciation or interpretation.

Accentuating the understanding that patterning of linguistic forms has the capacity to determine the structure and interpretation of literary works, Simpson agrees that "choices in style are motivated, even if unconsciously, and these choices have a profound impact on the way texts are structured and interpreted" $(2014, p .22)$. One is less concerned with the 'motivation' than with the fact that the "structure' of a text often productively generates concomitant interpretation. The outcome of a stylistic analysis is a prelude to this interpretation.

The author's accessible idiolect, as represented by the special application of linguistic features of transitivity, is the main concern of this article. The frequency of consistent contrast in the selected poems and as indicated in nominal references and verbal features is the main thrust of investigation in this paper. The contrast however focuses on the degenerative essence of deployed transitivity in the selected poems. In this regard, contrastive transitivity is examined in terms of how the ideational metafunction reflects a consistent manifestation of anticlimax or bathos. This is 
exemplified, for instance, in the descent from concreteness of terms to abstract forms in the choice of nominal references in Clark's poem, "His excellency, the masquerader" (HETM). In this poem also, there is a deployment of verbal forms (processes) in a degenerative progression from material to mental.

The ultimate aim of reading of any literary piece is appreciation, the latter of which is an appropriation of meaning or signification. However, in order to derive total appreciation of a literary piece, it is beneficial to the reader to appropriate what Lawal (2003) identifies as Total Stylistic Appeal (TSA). Thus, the analysis of what constitutes style may involve or account for apparent linguistic forms and features as well as more subtle forms of significant aesthetic value. While frequency of lexico-semantic and syntactic forms can be said to be easily accessible to an average analyst, the delicacy of meaning, semantic import or total significance accruing to a piece of literature may not be quite obvious to just any reader.

It is useful to make a clarification on the application of the two terms - contrastive and degenerative. The two terms are not applied in comparative or distinctive understanding but as a sort of semantic co-ordinates that illustrate a particular stylistic trend observable in Clark's selected poems. Simply stated, the degeneration from good to bad, or bad to worse, indicates a contrast in reference and process. Therefore, the analysis herein will focus on the occurrence and frequency of degeneration, the latter of which subsumes contrast.

\section{THEORETICAL FRAMEWORK}

Halliday's Systemic Functional Linguistics (SFL) offers the basic conceptual and theoretical framework for this article. Transitivity, which is an aspect of the ideational metafunction, is the main element of the analysis. The ideational metafucntion itself is a component of the semantic level of language. The focus on assessment of meaning or composite significance of the features is mainly concerned with the pattern and frequency of lexico-semantic forms as identified in the data. These lexico-semantic forms shall be limited to the nominal references and verbal features which constitute the participants and processes, respectively. In this way, transitivity becomes the pivot of the analysis.

Transitivity as expounded by Halliday in SFL theory is distinct from its construction in traditional grammar or other modern grammatical theories like TGG. According to Jeffries \& McIntyre (2010):

The syntactic system of transitivity is the central component in Halliday's functional grammar, which was conceived in relation to English and is thus perhaps peculiarly suited to that language, although the development of systemic-functional grammar theory and models is not so restricted (p. 72).

To traditional grammarians and perhaps any other grammatical theory (except, as already said, in SFL), transitivity may be an exclusive nature of the verb. In this regard, under this conception or idea, transitivity may relate to the feature of a particular verb being transitive - by having a direct object - or intransitive, in which case such a verb occurs without a direct object. Although Halliday recognizes the transitive and intransitive (or even di-transitive) nature of verbs, transitivity as he particularly conceives it goes beyond the verb to include linguistic forms or features indicating circumstance and nominal references. According to him, "transitivity is a component of the ideational function of language and captures or is indicative of the linguistic expression of processes, and of the participants (and, by extension, the circumstance) associated with them" (Halliday, 2002, p. 179). In further clarification on the idea of transitivity, Jeffries \& McIntyre explain that it "reflects the ideational meta-function, in which language represents the world in certain ways" (2010, p. 77). Representation ordinarily revolves around semantic component as reference. Transitivity is therefore a crucial component of textual cohesion of any piece of literature. Textuality or textual essence whether it occurs as carefully contrived form or comes as a flow of the natural order of the linguistic code, has the capacity to convey meaning and extend the aesthetic value of the piece of writing. Analyzing a poem in relation to transitivity offers a newer approach to textual analysis. This is probably the reason why Jeffries and McIntrye agree that "transitivity analysis can be helpful in characterizing aspects of style that no other tool has yet captured" (2010, p. 74). Consequently, the inherent meaning of a text is fully accessed only after a detailed assessment of the delicate import of transitivity features that constitute the text.

Delicacy is a crucial concept in SFL. The concept of delicacy applies to the inherent features of the word with respect to the details or specificity of its application or sense in usage. Halliday \& Matthiessen (2004) explain that "(d)elicacy in the system (of Systemic Grammar) is the analogue of rank in the structure" (p. 22). Under delicacy relevant connotations and denotation of a word are accounted for in a more detailed format in order to arrive at or derive total/maximum significance. This process involves a simple binary approach of plus or minus (+/-) semantic features. For instance, a noun can be viewed in terms of being +concrete, +multisyllabic; while a verb can be analyzed with respect to being finite, material, mental or behavioral. It is therefore the consideration of delicacy of lexical features in the analyzed poems that yield to the significance or stylistic interpretation of a contrastive and degenerative transitivity.

\section{Degenerative Transitivity}

Degenerative transitivity applies as a stylistic effect in a situation where transitivity features begin to manifest a contrastive and systematic redirection in meaning or delicate application such that what may have begun with the binary feature of plus (+) eventually culminates in minus (-) feature. The concept of Degenerative Transitivity (DT) is coined to account for an anticlimactic effect of words placed in contrastive succession. In such a situation, the essence of lexical forms manifests a downward contrastive movement. In Clark's "His Excellency, the Masquerader" (HETM), for 
instance, there is a clear regression in the delicate feature of nominal references from what can be termed concrete towards the abstract as the poem progresses. Thus, as transitivity features are presented in the poem, there is an indication of negative reference on the part of the voice. This negative reference underpins the thematic concern of the poet which is to upbraid, denounce or castigate the political class of the time. Another explanation for Degenerative Transitivity is in theta roles accruing to nominal references or Nominal Word Group (NWG). Thus, the frequency of nominal reference may regress from actor to beneficiary and finally end up as agent or instrument. The verbal features may degenerate from those that indicate mental processes to those that illustrate material or behavioral processes.

Degenerative transitivity is a stylistic feature which, although has not been popularized, can be objectively assessed in poems and other literary forms (especially poems). It can be said to belong to the delicate aspect of style which may or may not reflect a totally conscious manipulation of linguistic forms on the part of the language user. It is an ingredient of style when it is consistent and indicates a considerable connection with the thematic concern of the text in which it occurs. It is like motif, or can even be termed a form of motif.

At a superficial level, and as already stated, the concern with degenerative transitivity is as reflected in, first, the role played by indexed or referenced participants in a text. Such roles include those of actor, goal or beneficiary. Secondly, the analysis could be concerned with the type of processes indicated in the verbal elements of the text. However, at a more discrete level, and with respect to participants, the intention is an examination of the type of nominal reference, vis-à-vis abstract or concrete, animate or inanimate, human or non-human, etc.

\section{J. P. ClARK: THE MAN, THE WORKS}

Being one of the foremost Nigerian authors in rank with Wole Soyinka and Chinua Achebe, and unarguably the most productive poet south of the River Niger, John Pepper Clark's writings have received significant scholarly and critical enquiries. As writer, poet and dramatist, Clark has received such a generous attention that Eghagha (2004) admonishes that students and scholars should divest their attention from him and other such iconic authors like Soyinka and Achebe. In Eghagha's view, writing on Clark and these other authors could amount to a rehash of common opinions and thinking. Although one understands Eghagha's concern about the recycling of critical views on Clark or other such writers, there is however a conviction that works of literature possess a distinction which makes them yield to ever new insights so long as the analyst is highly motivated to derive newer significance.

Elechi Amadi, one of the earliest and celebrated creative writers in Nigeria and one who shares in the creek or rain forest background of Clark, expresses his delight in Clark's works. Amadi declares that he has "a soft spot for Clark's poetry probably because the poet writes about the kind of environment he (Elechi Amadi) grew up in" (2011, p. 256). This statement captures the consistent context of riverine topography that has proven a kind of shibboleth or stylistic marker for Clark as a creative writer.

Reiterating the opinion of Eghagha on the extensive presence and popularity of Clark in scholarly discourse, Iroegbu (2016) observes that:

Clark is a very accomplished poet who has about two hundred and ninety six titles to his credit. Not only is the poet prominent as one of the oldest still artistically productive, but also Clark occupies a very significant position as the numero uno poet in the whole of the Niger Delta (Nigeria) (p. 81).

Unarguably, in the hierarchy of most accomplished and iconic writers from Nigeria, Clark is a major of the tripod which includes Wole Soyinka and Chinua Achebe as the other members of the group. In a manner of speaking, the trio of Soyinka, Achebe and Clark tend to be particularly identified with the three genres of literature. Thus, while Soyinka and Achebe are recognized with drama and prose, respectively, Clark, although not completely lacking in these other genres, is disproportionally more engaged in poetry than with drama and prose.

Drawing attention to the conspicuous dearth in the linguistic appraisal of Clark's work, Eyo (2005) comments that: most of the critical views (on Clark-Bekederemo) concentrate on the traditional thematic approach to criticism, almost in complete isolation from language; the critics do not approach Clark-Bekederemo's poetry from the perspective of stylistic criticism (p. 22).

Eyo observes that this lack of linguistic approach has contributed to the poor understanding of Clark-Bekederemo's poetry. Quoting Anozie (1989), he maintains that since poetry is primarily a verbal approach to signification, its appraisal might be "insightful and rewarding if it is approached from a linguistic viewpoint" (2005, p. 23). This article, engaging in an analysis with a focus on transitivity or lexical forms, answers to the call for a linguistic approach to Clark. This approach is justified if considered in line with the observation of Udumukwu that a better analysis of the linguistic form in a text engenders a purer appreciation of the total significance such a text since language is the primary raw material for literature.

Speaking on the style of the poet, Yeibo (2011) concludes one of his essays, after a fairly extensive analysis of the "group patterns" in a selection of Clark's work, with the opinion that "the poet's style is foregrounded by the utilization of structural devices such as group types for encoding the meaning of his texts" (215). Yeibo is one of the few stylistic analysts who employ specific theoretical framework in their study of Clark's poetry. His works on Clark clearly applies a more linguistic outlook than Eyo's. Although Yeibo gives much credit to Eyo (1997), he does not indicate the latter's non reliance on any theoretical model. Thus, while Eyo gives an extensive account that bears slight and almost negligible marks of a linguistic approach, Yeibo sets out with a clear-cut methodology and theoretical framework as a 
popular approach to text analysis may require. This present discourse is therefore a continuation of the investigation into the stylistic dimensions of Clark's poetry, albeit in a slightly divergent direction.

\section{Methodology}

Twelve poems are selected in this study. The selection of the poems is guided by two main considerations. First, the poems exhibit features of contrastive transitivity. Secondly, the poems are randomly selected across the collections as contained in Full Tide which presents a compendium of Clark's poetic publication from his first works to those of latter period. The method of analysis involves extraction of the transitivity features as they are contained in the poem, indicating how these are engaged in a contrastive relation. Thus, simple lexical features which occur either as a single unit or in compound presentation are contrastively placed side by side and in order of their sequence to show a consistency. These features are limited to nominal forms, which present the participants, and verbal forms, which indicate the processes. In most instances nominal forms and verbal features are isolated and analyzed as they occur in particular poems. Sometimes, however, the two features are juxtaposed as they occur within a given work.

\section{DISCUSSION}

\section{A. Contrastive and Degenerative Transitivity in Nominal and Verbal Features}

Nominal features, as presented in the participant component of the ideational function in the language use, constitute one of the two parts in transitivity which illustrate the incidence of degenerative and/or contrastive sequence of lexical items in some Clark's poems. Some of these poems where there are indications of degenerative transitivity are those in which Clark presents pejorative views of subjects or persona. To this extent, the delicate semantic imports of these lexical items engender a reinforcement of the thematic concerns of the poems in question. This type of degenerative transitivity, which functional generates a sense of bathos, occurs in "His Excellency, the Masquerader" (HETM), "Tide wash" (p. 15), "Cuba confrontation" (p. 46), "Calcutta" (p. 110) and "The playwright and the colonels" (p. 145).

\section{B. "Tide Wash"}

"Tide wash" is one the poems inspired by the attendant social realities after the civil war. The poem is used to describe the estranged situation among citizens who were at one time buddies. Specifically, it is a reference to Clark's friends who supported and fought on the either side of Nigerian-Biafran war. Before the war, bonds of fellowship, scholarship and common identity held Clark and other colleagues such as Achebe and Okigbo together. But the civil war situation which pitched Clark's part of the Eastern region against their erstwhile kith and kin from Igbo land, like a tide, washed away all pretense of affinity.

The nominal references in "Tide wash" feature a clear instance of contrastive and degenerative transitivity as they sequentially occur. The notable nominal references here are:

stream

sun

fun

steam

sand

In terms of association or denotation, the term, 'stream', can be assigned such semantic significance as: full of life, reviving, gift of nature, serenity and benevolence. Much like 'stream', 'the sun' is suggestive of: life-giving, strength and vitality while 'fun', which rhymes with 'sun', relates to mirth, joy and friendship. However, in a degenerative sequence that calls up a sense of bathos, these positive terms of desirable references are soon to be succeeded by 'steam' and 'sand'. The reference, 'steam', suggests vapour which has little or no essence. It is an expended form. In the same vein, 'sand' is quick, lacking in strong support and of little or no value except if used in combination with other substances. This is degenerative nominal transitivity at an easily accessible or obvious level of semantics. However, at a more discrete level of semantic analysis, the sequence, stream - sun - fun - steam - sand, gives a sense of reference whereby we have two concrete nouns, stream and sun, being conjoined or linked with another set of concrete nouns, steam and sand. The linking term here is the nominal feature, fun, which is an abstract noun. Thus, there is a syntagmatic association indicating a sort of bi-polar relation. Moreover, the first set of nominal references is associated with location or place whereas the second set does not indicate such thing as particularity, place or location. Essentially, the term, 'stream', also suggests a flow or movement from one point to another. Thus, the movement is directional while 'steam', though might indicate movement, is non-directional. The two nominal features, 'steam' and 'sand' have the peculiarity of being only useful or productive if or when coordinated by an external force and especially in a combination with other substances. In contrast, 'stream' and 'sun' do not in any way need coordination in order to be useful or productive. They are autonomous and naturally life-giving/life-sustaining.

\section{C. "Cuba Confrontation"}


"Cuba confrontation" captures the infantile resistance and confrontation engaged in by Fidel Castro against the United States. Clark compares Castro to a courtesan pillow billed against a hammer head. Whatever Cuba deigned to do to America was like the futile attempt of the lizard giving the earth a blow with its head.

In "Cuba confrontation", and very much like "Tide wash", there is a clear indication of degenerative transitivity with linking features in-between. Two sets of nominal references occupy the bi-polar ends in a contrastive and degenerative transitivity. These are: 'harmer head' \& $(+)$ 'earth' and 'courtesan's head \& $(+)$ 'pillow'. In spite of the contrast, there is a form of semantic coupling for a 'total stylistic appeal', (Lawal, 2003, p. 159). This relationship of coupling for a stylistic appeal can be better appreciated if it is taken into consideration that while 'hammer head' (and 'earth') can be classified as hard and -human, 'courtesan's head' (and 'pillow') may be categorized as soft and +human. Degenerative transitivity is achieved wherein what begins as a concrete and very strong/threatening feature (hammer head + earth) progresses to an abstract term (blow) and finally culminates in a contrasting soft/appealing reference (courtesan's head + pillow).

\section{D. "Calcutta"}

"Calcutta" recaps the slummy situation in India whereby streets of "slime" share spaces with palaces of luxury. It is more or less a panoramic description of an environment of dirt as well as an implicit comparison of poverty against affluence.

In "Calcutta", there is contrastive and degenerative transitivity wherein the text begins with nominal references related to the semantic field of 'animate' but eventually downgrades to non-living and inanimate things. Thus, the frequency moves from "Cow" - man - lice - street - slime - slums, etc. These indicate contrastive cluster of semantic fields as can be seen in the sequence of ...man - lice ...slum - streets. Whereas the first set of lexical items (participant/nominal reference) indicates animate semantic reference, the second set exhibits an inanimate essence. The terms 'slime', 'bed' and 'bath' are inanimate, however, they do not generate the sense of 'place/location' as compared to their counterparts, 'palaces', 'slums' and 'streets'. This is why their occurrence serves the purpose of linking or conjoining.

\section{E. "The Playwright and the Colonels"}

"The playwright and the colonels" is a poem Clark applies as a response to Soyinka's perceived malicious writing on the former. Thus, after abandoning the initial attempt to get a redress through the law court, Clark applies the poem to castigate Soyinka. He depicts Soyinka as an inconsequential coward who was picked up like a rain drenched fowl and jailed by the military like a common criminal. The poem is thus a sort of diatribe to get back at Wole Soyinka

In "The playwright and the colonels", there is a stylistic appeal resulting from degenerative transitivity. This is particularly reflected in the appended speech of the persona (Soyinka) where the sequence involves nominal references including 'ride', 'wake', and 'race', which are all abstract in essence. These first set of nominal references is followed by 'friend' which is a concrete and an animate term; then, thereafter, occur 'pen' and 'tale' which are both inanimate/non-human. As they are presented, they are paradigmatically related considering the fact that they are modified by the same deictic term, 'my', with the only exception of 'ride' which has "A triumphant" as its modifier. Thus we have:

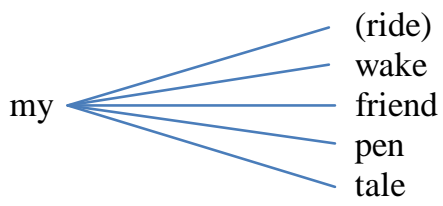

Completing the set of degenerative transitivity are the abstract references, 'a grape-shot' and 'the end'. Therefore, but for 'a grape-shot' which features compounding, all the nominal features above are mono-syllabic. The participant, 'friend', which is the departing point of contrastive degeneration, also serves as a 'semantic field linker' (SFL). Significantly, every other nominal feature except 'friend' is either non-human, intangible/abstract or inanimate.

\section{F. "New Year"}

In the "New Year", Clark's main concern is with the characteristic and inevitable drift of the human towards old age and transition. The poem uses the imagery of the annual flood which is the traditional unit of time among the Niger Delta people. The drifting "water lettuce" headed in an inevitable movement to the sea depicts the journey of life. To the human, as the flood continues in its unpreventable movement so does "insidious" health challenges creep in unannounced to exacerbate the degeneration.

In the poem "New Year" (395), contrastive participants and processes that indicate degeneration are clearly evident. At the nominal level, the sequence follows: 


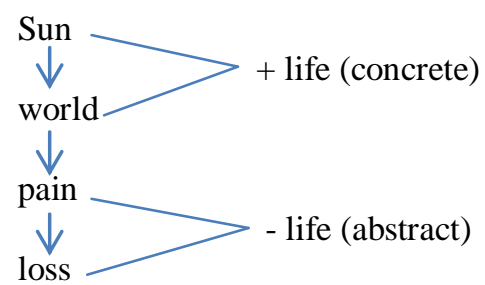

The participants (nominal forms) above occur as actors rather than beneficiaries; the first two, "Sun" and "world", do not indicate direct beneficiaries, in other words, they are applied intransitively.

The processes in "New Year" seem not to follow the exact trend of the participants. This is because, in terms of transitivity, the sequence of the process indicates two material processes, "came" and "fill", sequentially enclosing two/three other relational verbal forms, "did", "will" and "is". The only way one might observe a degeneration is in the fact that whereas "came out" shows the "sun" as engaged in a transitory movement indicating dynamism, "fill" does not show an active state with respect to the nominal forms/participants with which it occurs. In other words:

Pain and loss fill my plate

as an expression does not indicate the abstract nouns (Pain \& loss) as doing the 'filling' (of the plate), a feature/quality which is in contrast with the "sun" which does the "coming out'. Comparing the poem, "Tide wash", with "New Year", the systematic patterning of contrasting processes takes a different dimension in the latter. Here, the contrast is more of a juxtaposition of features which culminates in a final negative process.

\section{G. "His Excellency, the Masquerader" (HETM).}

HETM is a castigation of the Nigerian political class in respect of their inability to foster a strong union among the disparate and diverse components of the nation. The poem, thus, highlights the failure of the political representative especially in the first republic to institute a strong and formidable union at the inception of nationhood. Rather than constituting a rallying point for a strong socio-political identity/polity, the political class are compared to "straw and wind" ostensibly fronting a false mask of formidability behind a sand castle. To accentuate the theme of disgust and disapproval in HETM, there is a stylistic combination of contrastive and degenerative transitivity at both the participant (nominal) and process (verbal) level. The total number of verbs deployed in this poem is as represented in the table below:

TABLE 1

TRANSITIVITY OF PROCESSES IN HETM

\begin{tabular}{|l|l|l|l|l|l|}
\hline Stanza & Intransitive & Transitive & Copula & Non-finite \\
\hline $\mathbf{1}$ & serves (2) & & & to ford \\
\hline $\mathbf{2}$ & stands (2) & & & \\
\hline $\mathbf{3}$ & drop & & should be & \\
\hline $\mathbf{4}$ & & & shows & & (stands) \\
\hline $\mathbf{5}$ & & worship & & (drop) & (shows) \\
\hline $\mathbf{6}$ & & & & take off & (worship) \\
\hline & $\mathbf{5}$ & $\mathbf{1}$ & $\mathbf{2}$ & $\mathbf{2}$ & -- \\
\hline
\end{tabular}

At the level of process, one easily notices a regressive movement in the semantic value and delicacy of the verbal features. There is just one verb, worship, which is both transitive and finite. And, this verb does not indicate coordinated mental or material process. The nominal form, "they", which is the subject of the verb, "worship", occurs as a pronoun without an antecedent.

In Ojoto, they worship the mask

Who is the "they"? Obviously, "they" makes an anophoric reference to the people of "Ojoto", yet "they" could mean more, or even less, than the entire people of Ojoto.

The degenerative trend in the application of the verbal forms is illustrated in the diagram, showing a downward stroke below:

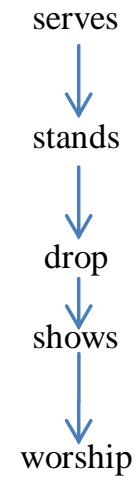


There is evident degeneration in transitivity as the verbal items which begin in "serves" culminates in "worship". The term, 'serves', shows activity, although the activity is non-directional. But, the next verb, "stands", does not indicate any coordinated activity or action. This succeeding verb rather semantically denotes an immobile, resting or stationary position. Like 'serves', it is material (or behavioral) but it indicates neither coordination nor direction. Like the ones before it in the order of sequence, "drop", the next verb after "serves" and "stands", does not indicate a coordinated or directional activity. Moreover, the Subject related to the verb does not act by volition. This feature is obtainable in "shows" which likewise does not suggest an active Subject. Finally, "worship" is more of a behavioral or mental process than material. If it is factored as a verb having a common origin with an abstract nominal reference, religion, one may easily notice the contrastive and degenerative essence from concrete to abstract or intangible.

The sequence of the nominal forms in HETM illustrates a pattern of coordination applying the conjunction, "and". In this instance, as in the previous observations, there is both degeneration and contrast. The diagram below indicates this frequency:

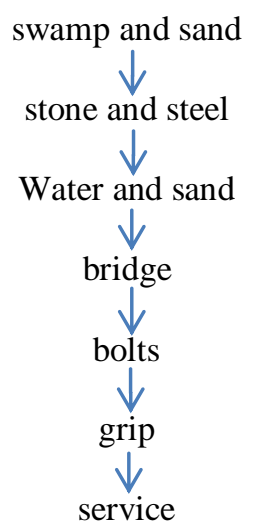

One notices contrastive and degenerative application of transitivity at two levels. At the syntagmatic level, it may be observed that there is a shift from coordination to singularity in the frequency of the nominal forms. In other words, the frequency of the nominal word groups (NWG) which began as a combination of words latter trickles down to single forms. This instance underscores the thematic preoccupation of the poem which is the upbraiding of the political class which in the beginning promised national unity but at the end offered self-aggrandizement. At a less discrete level of transitivity, it is easy to identify the shift from concreteness to abstract; a shift from formidability to immaterial.

\section{H. "Partners"}

The poem, "Partners", consists in five short lines. It is used to review the challenges of dissatisfaction that comes with marriage. At some point in time, according to the poem, every couple wishes they had made a different choice in their matrimony. The mental process, "wish", functions as a keyword in the poem.

In "Partners" (Full Tide, p. 211), there is a stylistic deployment of verbal features that tend to a degenerative or contrasting sequence. Here also, like some of the illustrations above, there is a kind of bridge which separates the two contrasting features. The verbs deployed here are: looked, know, find, and wished.

In terms of delicacy, all verbs deal with perception or what is called a mental process. However, whereas looked indicates a directional perception almost correlative of an act or material process, wished is a more or less internalized process which does indicate the reference acting upon something. The diagram below captures the polarity between the two features and the bridge offered by the uninflected terms, know \& find.

\section{I. "Stranger in the House"}

"Stranger in the house" is applied to capture the sense of estrangement in a hitherto familiar environment. In contrast to those to whom the environment was the only home they know, Clark observes hostile changes. These changes may be referring to the envy, jealousy and unhealthy rivalry among competing half-brothers and step-mothers.

In the poem, "Stranger in the house", there is a contrastive deployment of both verbal features and nominal references with a stylistic touch displaying what looks like a gap or bridging feature. This can be recognized at the syntagmatic presentation of 'fire - stone - snake' and 'burns - weighs - chills'. The two instances above illustrate the nominal features and the verbal features, respectively. Another poem which shows peculiarity of contrastive verbal features in sequence is "Other women". The main verbs deployed here are feeds, falls and glows. The contrasting verbs in delicate transitivity are feeds and falls. Although all material processes, these verbs are in contrast because whereas one indicates a self-motivated act, the other does not indicate an act out of the volition of the actor. The verb, "glows", offers a bridge because it does not indicate a material process.

\section{J. "Sacrifice"}

"Sacrifice" illustrates a pessimistic outlook where the poet doubts the love and dedication to the country. The nation, in contrast to what held at its inception just after colonial rule, the nation has lost the hold or attraction for selfless service or sacrifice. Clark questions the propriety in withholding this information from his children. 
In the poem, "Sacrifice", the deployment of contrastive transitivity as a stylistic feature presents as kind of bathos in the sequence. Here, the contrasting nominal references are life and property. These two forms are bridged by the term, limb. Diagrammatically, this can be represented thus:

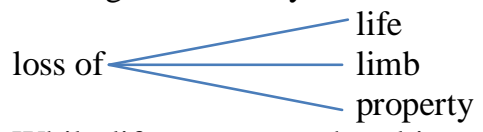

While life represents the ultimate loss, property is the least that can be lost. Although the loss of life and limb is permanent, the latter (loss of limb) could be borne. However, unlike life and limb, property could be replaced. Therein exists the semantic contrast existing among these nominal references.

\section{K. "Streamside Exchange" and "Abiku"}

Other poems where Clark deploys contrastive and degenerative transitivity to stylistic effect include "Streamside exchange" and "Abiku". "Streamside exchange" offers a surrealistic exchange between an anxious child and a dispassionate bird. The child sets out to make enquiry as to the whereabouts of its mother. The bird, in applying the metaphor of the running tide and continual market - events which indicate the situation of coming and going in an endless cycle - categorically tells the child that what occurred was beyond the comprehension and control of the child. "Abiku" on its part captures the phenomenon of infant mortality and the helplessness of a mother who was condemned to have an evil child engaged in a vicious cycle of repeated birth and death. The child's engagement in the repeated process of coming and going brings about a state of disillusionment on the part of its mother.

In "Streamside Exchange" (SSE), for instance, there is a subtle breach of politeness principle on the part of the bird who responds to the child's inquest with a response characteristic or correlative of a WH interrogative. The bird which, perhaps, feels slighted that a mere child directs a polar interrogative to it responds in a manner drastically contrasting in the polite way in which the child presents its part of the conversation. The mental process ascribed to the child (human) contrasts with the material process which the bird assigns to other participants (non-human) and the child's mother. Tables 2, 3 and 4 feature the participants and processes captured as transitivity in the bird's response to the child's simple question.

TABLE 2

PARTICIPANT TRANSITIVITY IN THE BIRD'S RESPONSE IN SSE

\begin{tabular}{|l|l|l|l|l|l|}
\hline S/N & Participant & Thematic status & Nature & Process & Process type \\
\hline 1 & You & Theme component & Human/animate & know/bother & Mental (negative) \\
\hline 2 & Tide & Theme component & Inanimate & come/go & Material (positive) \\
\hline 3 & market & Theme component & Inanimate & come/go & Material (positive) \\
\hline 4 & your mother & Rheme component & Human & come/go & Material (positive) \\
\hline
\end{tabular}

TABLE 3

PROCESS TRANSITIVITY IN THE BIRD’S RESPONSE IN SSE

\begin{tabular}{|l|l|l|l|l|}
\hline S/N & Process & Type & Polarity & Co-reference \\
\hline 1 & know/bother & Mental & Negative & Child \\
\hline 2 & come & Material & Positive & Tide, market, your mother \\
\hline 3 & go & Material & Positive & Tide, market, your mother \\
\hline
\end{tabular}

The incidence of contrastive transitivity above is registered in the sense of mental vs. material; and negative vs. positive.

What occurs in SSE is similar to that which plays out in "Abiku". In "Abiku", the voice or poet/persona contrastively ascribes material processes to the Abiku and other (non-human) participants and a positive mental process to itself. The import of this is that the voice or poet/persona is the only one capable of cognitive act or contemplation while the Abiku and others such as bats, owls and floods could only engage in material processes. Table 4 illustrates this ascription of process types to participants:

TABLE 4

TRANSITIVITY OF PARTICIPANTS AND PROCESS

\begin{tabular}{|l|l|l|l|}
\hline S/N & Participant & Process & Process Type \\
\hline 1 & Abiku & Coming, going, stay out, follow, step in & Material \\
\hline 2 & Speaker, poet/persona (We) & know & Mental \\
\hline 3 & other (fingers) & reach & Material \\
\hline 4 & bats \& owl & tear & Material \\
\hline 5 & flood & brim & Material \\
\hline
\end{tabular}

In "Abiku", there is a contrastive deployment of rhematic and thematic forms such that all nominal forms, except the one that has the voice or poet/persona as Subject, occur as part of the rheme rather than the theme. Thus, although nominal forms which account for participants in transitivity are shown as indicating activity or being acted upon, none of these feature in an unmarked clause. In other words, these participants, including Abiku which is the ostensible subject of discussion, never featured as Subject. 


\section{CONCLUSION}

The significance of this article can be accessed and assessed in two ways. First, it offers another method in the study of lexical features whereby frequency and positional essence of words are highlighted as significant indices by which extended meaning can be generated in literary texts. This is comparable to concretization. The only difference is that while concretization is, to an extent, paralinguistic, degenerative transitivity is purely lexico-semantic. Here, selection of words is observed as a transposed stylistic undertaking which is capable of enhancing thematic pre-occupation of the literary text. This much is indicated by Nørgaard, Montoro and Busse (2010, p. 31) when they recognize that the making of a literary meaning can derive from the "typography, layout and visual images" of a text. The layout and enhancement of visual images arising from the systematic deployment of nominal references and verbal features are practically illustrated in the poem HETM. Thus, the clearly indicated shift from lexical forms denoting and connoting concrete and formidable imagery to those offering abstract essence can be applied in reading poetry both for pedagogy and literary appreciation. The total essence or overall significance of words is often better appreciated when placed against contrasting forms. Moreover, it is hardly contestable that although Clark as a writer holds an iconic position in the Niger Delta in particular and in Nigeria as a whole, compared to the works of Soyinka and Achebe who constitute the other two components of the artistic tripod in Nigerian literature, his poetry has been given less linguistic attention than is commensurate to the volume and expanse of his career as a creative artist. Thus, this article is in continuum, albeit in slightly divergent method to what has been done by previous critics such as Luke Eyo, Ebi Yeibo and others. Although this work adopts a linguistic approach, the marriage of the thematic concern with the frequency and sequence of linguistic forms enhances the literary quality of the article.

In creative or aesthetic writing, writers put out their work, language, technique, form, content, etc., while critics and analysts interpret the work based on what has been presented by the writer. Meaning(s) potentially generated by a writer's use of language may be diverse and divergent. This is because language is dynamic and interpretation is often conditioned by context immediate and mediate. Indeed, it may be too prognostic to conclude that Clark's poetry, or any literary piece for that matter, could hold the same interpretation to all analysts at all times. Since the topics of transitivity and delicacy were not part of burning linguistic issues at the time of the composition of most of these poems, the foregone analyses in which the poems yield to the concepts constructively validate the universality in application of grammatical theories and concepts. Thus, the susceptibility of the poems to the concepts gives credence to the understanding that language use, in aesthetic or other contexts, comes with an appreciable degree of systemic consistency, predictability and a kind of governed paradigmatic collocation which issues from the subconscious rather than the conscious. In other words, sometimes, words and expressions take or assume forms and interpretation which are somewhat autogenic. Considering that what constitutes observable patterning might not have originated from conscious manipulation on the part of the writer, McMenamin (2002) agrees that style is consistent with linguistic features that are remarkable. The remarkable frequency of words, in relation to transitivity, begins to play out what can be seen as independent interpretations after the writer has done his bit. Was there a conscious effort on the part of the poet, J.P. Clark, to systematically assemble words in such a way that the end result would be a "degenerative transitivity"? One may be unable to answer this question satisfactorily, yet, by the forgone analysis, it is evident that there exists a patterning in the frequency of words and expressions that yield to this conclusion.

\section{REFERENCES}

[1] Amadi, E (2011). “A celebration of J.P. Clark's 50 years of artistry”, In Songs of Gold: Fresh Perspectives on ClarkBekederemo, Ododo S.E. \& Mbajiorgu G. (eds.), pages 255-258.

[2] Anozie, S (1985). "Equivalent structures in Soyinka's poetry: towards a linguistic methodology in African poetry criticism". Research in African Literatures, Vol.16, No.1 pages 21-35

[3] Clark, JP (2010). Full tide. Ibadan: Mosuro

[4] Eghagha, H (2004). "Unmasking the masquerade and extending the canon of Nigerian literature". In The domestication of English in Nigeria Awonusi, S. \& Babalola, E.A. (eds.). Lagos: University of Lagos Press, pages 480-497

[5] Eyo, L (1997). “J.P. Clark-Bekederemo's poetry: a study in stylistic criticism”. Unpublished PhD Thesis, University of Port Harcourt

[6] Eyo, L (2005). J. P. Clark-Bekederemo's poetry: A study in stylistic criticism. Uyo: Scholars Press

[7] Halliday, MAK (2002). On grammar. London \& New York: Continuum

[8] Halliday, MAK and Matthiessen, C (2004). An introduction to functional grammar, London: Edward Anold.

[9] Iroegbu, O (2016). "Of faces and phases: a stylistic examination of the water/river motif in J.P. Clark's poetry". Ife Journal of the Humanities and Social Studies, 3 (1): 81 - 95.

[10] Jeffries, L and McIntyre, D (2010). Stylistics. London: Cambridge University Press.

[11] Kamalu, I (2018). Stylistics: theory and practice. Ibadan: Kraft Books Limited.

[12] Lawal, A (2003). "Pragmatics in Stylistics: A Speech-Act Analysis of Soyinka's 'Telephone Conversation', in Lawal, A. (ed.) Stylistics in Theory and Practice, Ilorin: Paragon Books (Publishers).

[13] McMenamin, GR (2002). Forensic linguistics: advances in forensic stylistics. Boca Ranton: CRC Press.

[14] Nørgaard, N, Busse, B and Montoro, R (2010). Key terms in stylistics. London: Continuum.

[15] Simpson, P (2014). Stylistics: a resource book for students. London: Routledge.

[16] Udumukwu, O (2015). Literary theory and criticism: an introduction. Port Harcourt: Charles-Martins Higher Education 
[17] Yeibo, E (2011). “Group types as style markers in J.P. Clark-Bekederemo's poetry”. In Songs of Gold: Fresh Perspectives on Clark-Bekederemo, Ododo S.E. \& Mbajiorgu G. (eds.), pages 202-218.

Obinna Iroegbu $(\mathrm{PhD})$ is a Lecturer at the Department of English and Literary Studies, Federal University, Oye-Ekiti, Ekiti State, Nigeria. He holds a First Degree in English Studies from the University of Port Harcourt. His Master's and PhD, obtained from Ekiti State University and University of Port Harcourt, respectively, were on J.P. Clark's poetry. He has published a number of journal articles on Clark's poetry and other issues in language and literature. Dr Iroegbu's main research interest is in the language of literature (stylistics). 